\title{
Erratum to: MicroRNAs: Novel Regulators of Oligodendrocyte Differentiation and Potential Therapeutic Targets in Demyelination-Related Diseases
}

Jia-Su Li $\cdot$ Zhong-Xiang Yao

Published online: 21 January 2012

(C) Springer Science+Business Media, LLC 2012

Erratum to: Mol Neurobiol

DOI 10.1007/s12035-011-8231-z

The original version of this article unfortunately contained a mistake. The affiliation of Jia-Su Li was captured incorrectly. The correct author's affiliation now appears below.

The online version of the original article can be found at http://dx.doi. org/10.1007/s12035-011-8231-z.

J.-S. Li

Department of Physiology, Squadron 4 of Cadet Brigade, Third

Military Medical University,

Chongqing 400038, China

Z.-X. Yao $(\bowtie)$

Department of Physiology, Third Military Medical University,

Chongqing 400038, China

e-mail:yaozhx@yahoo.com 